AVANT, Vol. XII, No. 2

ISSN: 2082-6710 avant.edu.pl/en

DOI: 10.26913/avant.2021.02.06

open $\boldsymbol{\sigma}_{\text {aCCESS }}$ aVs?

\title{
Somatics: Practices Toward Developing Environmental Empathy
}

\author{
Rebecca Weber \\ University of Auckland \\ New Zealand \\ b.weber@auckland.ac.nz
}

Received 16 July 2020; accepted 14 December 2021; published 31 December 2021.

\begin{abstract}
This article discusses how somatic practices, and in particular, eco-somatic practices, may develop environmental empathy. Using a critical abductive approach, it weaves together frameworks of ecocriticism, embodied and situated cognition, and somatic practices, and presents examples of influential eco-somatics practitioners Sandra Reeve, Praptro Suryadarmo, Andrea Olsen, Joan Davis, and Helen Poynor. Drawing on perceptual psychology (Sewall, 1995), it argues that eco-somatic practices such as theirs, through attending to sensation in natural environments (Bettmann, 2009; Kramer, 2012; Laidlaw \& Beer, 2018; among others), develop ecological perception and awareness of both inner and outer sensation. In so doing, this article offers an explanatory hypothesis of how eco-somatic practices cultivate a sense of environmental empathy.
\end{abstract}

Keywords: somatics; somatic practices; eco-somatics; environment; ecology; cognition; perception

\section{Introduction}

We are currently in the midst of the Anthropocene - the geological epoch characterised by humans' impact on the environment (Crutzen 2006), including the troubling anthropogenic climate change and global warming that researchers attribute to human factors (Rosenzweig et al. 2008). As such, it is more imperative than ever that humans develop a sense of relationship with, and empathy towards, the environments they live within. How do we develop an ecocentric approach, in which humans are understood as interrelated with the larger environmental world (Taylor 2011)? Some researchers have theorised that humans create empathic relationships with nature (Silva and Phillipi 1998, Wahlstrom 1998, as cited in Lithoxoidou et 
al 2017), while others (Hungerford and Volk 1990, Lithoxoidou et al 2017, Sobel 1996) argue that extending empathy towards the natural environment is essential to responsible environmental behaviours, and further argue that environmental empathy may be developed through educational methods. I propose an additional alternative in this article. Taking a critical psychological approach and using an abductive 'logic of inquiry' (Stanton Rogers 2009, p. 336), I identify influential eco-somatics practitioners and connect commonalities in their approaches to situated cognition theories to generate an explanatory hypothesis (Shank 1998, Stanton Rogers 2009) that somatic practices may contribute to the development of environmental empathy.

\section{Ecocriticism}

Many theorists argue that the current state of environmental crisis comes as a result of a dichotomy between human and nature. This binary positions human as distinct from, and superior to, other forms of nature (Schultz, 2002), and with nature there to be exploited by humankind for their own purposes (Shultis \& Heffner, 2016). Nature and culture are often represented as opposites, with human-made artefacts, systems, and processes viewed as both intellectually and morally superior to those found in nature. Humankind is granted agency while the natural is subject only to following predefined laws and instincts.

The first ecologists bringing attention to this bias date back to the British Romanticism of the 1790s and the American transcendentalism of the 1840s (Barry, 2002). Activists created the first green organisations in the late 1800s and early 1900s. Eco-criticism, or 'green theory,' scholars have long called into question the orthodox assumption that the world is socially constructed, repudiating a belief in 'constructedness' which also, therefore, calls into question the hierarchy of the constructed-by-human over the naturally occurring. This is not, however, as Barry (2002, p. 253) argues, 'a naïve "pre-theoretical" notion of nature,' rather ecocritics deeply engage with the complexities presented by nature, culture, and the spaces in between. Human bodies, being both 'natural' or biological in one sense, and culturally defined in others (Clifford, 2008; Thomas, 1995; Vannini \& Waskul, 2006) offer prime subjects for ecocritical investigation.

Ecocritics have adopted the term 'more-than-human,' first coined by David Abram (1996) in The Spell of the Sensuous, to describe the remit of their work beyond human culture and constructions. The central idea of more-than-human is a rejection of the human-nature binary and reification of the interconnectedness of life and environment generally. Many ecocritics demonstrate how connecting to the more-than-human enhances a sense of self, scope of justice, and connection between self and the environment, and also increases altruism and sense of belonging (Laidlaw \& Beer, 2018). Noteably, Lailaw and Beer (2018, p. 285) point out that, 'recognizing our inclusive ecological identity and relational closeness to nature lead[s] to increased feelings of empathy.' This sense of connection and relation to nature and the morethan-human might be thought of as environmental empathy, or what Tam (2013, p.93) describes as 'empathy with nature.' Tam defines this as 'the understanding and sharing of the emotional experience, particularly distress, of the natural world' (ibid.). Though I argue environmental empathy includes both positive and negative experiences, I agree with Tam in that environmental empathy, as with other forms of empathy, involves both cognitive and affective 
components. Notably, environmentalist David Sobel (1996) has argued for the role of empathy in environmental education and of direct experience in developing environmental empathy. This article examines whether certain embodiment practices may offer such a direct experience, developing this empathetic connection to the more-than-human-- and if so, how?

As Robert Bettmann (2009) notes, valuing somatic knowledge is key to overcoming the human/nature binary. Further, as Laidlaw and Beer (2018, p. 285) argue to develop ecological empathy, on must 'engage in an embodied connection through their multi-sensory feeling body, not just their thinking mind.' Further, they note that it is in bodily doing of certain practices, such as somatic practices, that leads to future action, claiming, 'somatic dance experiences offer an antidote to society's disconnection to the more-than-human' (Laidlaw and Beer, 2018, p. 285).

\section{Somatic Practices}

The somatic dance experiences they reference come from the field of somatic practices. Derived from the Greek somatikos, the word somatic references the living body. The term was first used by Thomas Hanna (1970) to describe mind/body integration as experienced from the first-person perspective and came to name the field of study of the soma (body) as experienced through this perspective (Eddy, 2009). Somatic work is founded on the belief that soma is a fluid entity that responds plastically to both internal and external stimuli (Hanna, 1979). Perception of subjective, felt-sensation is at the core of all modalities practiced today under the umbrella term somatics (Brodie \& Lobel, 2006; Eddy, 2002, 2009).

Because of the focus on the body in somatics, research on somatics has largely found its academic home in dance and performance studies, though it is also practiced in community and client contexts and has been developed by practitioners and academics alike. Some examples of well-known somatic practices include Body Mind Centering, Laban Bartenieff Fundamentals, Alexander Technique, Rolfing, the Feldenkrais Method, Ideokinesis, and Skinner Releasing Technique as well as open-framework approaches such as Authentic Movement and embodied anatomy; these are but a few of the many somatic disciplines practiced today. ${ }^{1}$ All approaches share underlying ideologies that define them as somatics, such as a global focus on principles over techniques of movement (re)education (Brodie \& Lobel, 2012; Johnson, 1986), goals toward greater well-being and awareness (Brodie \& Lobel, 2004), and an emphasis on individual agency rather than 'set' movement patterns. Indeed, there is such an overlap in founding principles that many today incorporate multiple modalities within their somatic practices.

\footnotetext{
${ }^{1}$ For more information on the range of somatic practices, readers may find referring to the International Somatic Education and Therapy Association (ISMETA) helpful, in addition to the academic journal Dance and Somatic Practices.
} 


\section{Cognitive Models}

Because of its emphasis on subjective perception, somatic practices are well aligned with certain third-wave models of cognition (Batson \& Wilson, 2014; Weber, 2018, 2019). As Batson and Wilson (2014) trace, cognitive science has evolved through three distinct historical periods: the first being computationalist (in the 1950s-1970s); the second, connectionist-joining neural networks and dynamic systems theory in the 1980s and 1990s; and finally, inclusion of the second- or third-generation embodied cognition. However, as they state, computational, mathematical models which neglect body and movement in cognitive processing 'still hold primacy' within the cognitive science field (2014, pp. 40-41).

In these models, cognitive science views the brain as a computational system, with processing happening in neural networks and the body being the 'output' mechanism. Lawrence Shapiro outlines the historically shared tenets of cognitive science, stating that they reveal a commitment 'to a computational theory of mind' where the mind operates algorithmically on 'symbolic representations,' or data input to the brain to process, and subsequently output back into the body from the brain (2011, p. 27). All cognitive processing, he states, 'begins and ends where the computational processes touch the world' - a perspective which has been criticised for being solipsistic (ibid., p. 26). As Shapiro's observation illustrates, historically cognitive science was generally unconcerned with the body or environment and could therefore justify a focus on the brain without regard for anything beyond - thus strictly adhering to, and reifying, the Cartesian hierarchy of mind over body. Given this narrowing of perspective, the ways in which 'traditional' cognitive science has been challenged or questioned-i.e., criticised for being too narrow or reductionist—become readily apparent.

In recognition of these critiques, cognitive science began to evolve. Though computational models are still widely recognized, since the 1970s, cognitive scientists have begun to realize that cognition is contextual - of the mind, but also of the body and beyond. The idea that movement - and embodiment - is central to cognition is revolutionary. The shift from thinking of brains as computational systems to situating them in an integrated, dynamic relationship with our physicality is a major shift in scientists' understanding of cognition. The terminology used to distinguish this integrated approach from the dualistic empiricism of traditional cognitive science is embodied cognition or situated cognition. This form of cognition, as mentioned above, aligns with somatic practices. Wilson and Foglia (2011, n.p.) maintain that embodied cognition research works 'represent a serious alternative to the investigation of cognitive phenomena' and 'challenge dominant views of the mind, such as the computational and representational theories of mind, at the heart of traditional cognitive science' (ibid.).

\subsection{Embodied and Situated Cognition}

Neurophenomenologist Francisco Varela championed this anti-reductionist perspective on embodiment, arguing that the mind is fundamentally inseparable from subjective experience, its biological embodiment, and its situated context. It was Varela who coined the term embodied cognition to include both the biological and contextual body in cognitive processing (Batson \& Wilson, 2014, p. 42; Varela et al., 1991). The text The Embodied Mind, which 
Varela co-authored with Thompson and Rosch (1991), has been called an 'urtext' within embodied cognition (Shapiro, 2011, p. 52). In it, the authors reject traditional computationalist views of cognition and put forth an argument for cognition as 'embodied action:'

By using the term embodied we mean to highlight two points: first that cognition depends upon the kinds of experience that come from having a body with various sensorimotor capacities, and second, that these individual sensorimotor capacities are themselves embedded in a more encompassing biological, psychological, and cultural context. By using the term action we mean to emphasize once again that sensory and motor processes, perception and action, are fundamentally inseparable in lived cognition. (Varela et al., 1991, pp. 172-173)

In this theory, as an organism moves through its environment, its movement creates new perceptions which then reveal more opportunities for action, subsequently creating more movement and new perceptions again. This loop can continue ad infinitum for the duration of an organism's life, thus shaping its experience of being in the world from birth to death. Additionally, the perceptual systems of an organism will shape what types of motion, perception, and opportunities will arise. The affordance of action is directly dependent on an organism's perception. Thus, the perception-action loop, as self-directed and self-shaping, means that perception and action are coupled — as Varela, Thompson, and Rosch state above, 'fundamentally inseparable in lived cognition.'

Embodied cognition, because of the influence of phenomenological subjectivity (unlike earlier cognitive models), contends that the brain is an integrated dynamic system and is responsive to the moment-by-moment embodied dynamics of our lives. As Raymond Gibbs (2005, pp. 9 10) highlights, 'Understanding embodied experience is not simply a matter of physiology or kinesiology (i.e., the body as object), but demands recognition of how people dynamically move in the physical/cultural world (i.e. the body experienced from a first-person, phenomenological perspective).' Thus, in embodied cognition, researchers are not denying the role of the brain in executing higher-order processing, but maintaining that the brain is not the only corporeal actor facilitating these processes. And furthermore, the idea that cognition is dependent upon our unique, subjective, phenomenological experience again aligns with somatic practices, and situates cognition within a contextual environment.

Embodied cognition, however, like many emergent and emerging fields, lacks distinctioni.e., the field is still defining itself, and terminology is shared and used with different interpretations of its scope. As such, it, too, houses several strands of thought-what cognitive scientist and philosopher Lawrence Shapiro identifies as 'the remarkable multiplicity of ideas [around the definition of embodiment] that have been hailed in the name of embodied cognition' (2011, p. 51). Each of these strands falls under Wilson and Foglia's (2011) broad sense of cognition inclusive of the para-mental, which is termed situated cognition (Robbins \& Aydede, 2012; Wilson \& Foglia, 2011).

Situated cognition includes embedded, embodied, and extended cognition. Though the terms have similarities, are closely related, and may often be mistaken as interchangeable outside of the cognitive science communities, embodied cognition is not the same as embedded cognition nor as extended cognition. Embodied cognition, as emphasized above, includes the body beyond the brain. Embedded cognition distributes cognition both mentally and within the environment beyond the body - like how a chef can offload some of the cognitive processing, say 
for instance the order of ingredients to be added, of cooking a particular dish by laying out the kitchen in a particular manner. The thesis of extended cognition is the claim that cognitive systems themselves extend beyond the boundary of the individual organism. In this view, features of an agent's physical, social, and cultural environment can do more than distribute cognitive processing: they may well partially constitute that agent's cognitive system (Wilson $\&$ Foglia, 2011). In the theory of extended cognition, humans (and other organisms, presumably) are not inseparable from the interpersonal, ecological, and political environments that shape themselves and thus their cognitive processing and biases.

This situated approach to understanding cognition clearly has links to ecocritical theories; by entwining the body and environment with any kind of 'mental' processing, the organism becomes a part of a larger system creating cognition. The body as- and in-environment is a central part of this. As mentioned above, the first-person subjective experience emphasised in somatic practices also aligns with the anti-Cartesian and the phenomenological subjectivity upon which situated cognitive theories lie (Weber 2019). It therefore also re-defines the naturehuman binary — or rather, eschews it altogether. Highlighting the human-nature divide, Gibbs states, 'Cartesianism has also led to the romantic view of the body as the last bastion of what is natural, unspoiled, preconceptual, and primitive in experience. Bodily movement is viewed as behaviour, with little relevance to language, thought, or consciousness, and not as meaningful action' (2005, pp. 3-4). Yet, theories like situated and embodied cognition as well as approaches like somatic practices have much common ground in rejecting Cartesian hierarchies and reclaiming the body, its movement, and its environment as meaning-making agents in cognition—be though they may, 'natural.'

There are a number of somatic practitioners whose work inhabits this shared ground between ecocritical and situated cognition philosophies. These practitioners approach their artistic practice as a balance between body and nature, encouraging a felt and experiential awareness of our innate situated-ness that aligns with both embodied cognition and ecocritical models. Though not all name this alignment, many practitioners do explicitly recognise their approaches as ecological or environmental in nature. Though identifying all somatic practitioners whose work develops environmental empathy is not possible, I will highlight a few key practitioners who have had great impact on the somatics field by way of their example and teachings.

\subsection{Sandra Reeve and Prapto Suryadarmo}

Sandra Reeve is a self-described 'movement artist-researcher-educator-and-facilitator,' a senior registered dance movement psychotherapist (UKCP), and an author (S. Reeve, 2016d, 2016a). Reeve came to Somatics primarily through theatre, particularly the Grotowski method (S. Reeve, 2016d). She holds a PhD in Performance Practice that examined the relationships between 'notions of self, body, environment, change, habit, and choice' at the University of Exeter, where she is also an Honorary Fellow, and where she has lectured in performance and ecology (S. Reeve, 2016c). Reeve has published Nine Ways of Seeing a Body (2011a) and the edited collection Ways of Being a Body: Body and Performance (2013) alongside several other academic texts (S. Reeve, n.d., 2011b, 2014a, 2014b, 2015).Reeve is the creator of Move into 
Life (S. Reeve, 2016e), which is her primary somatic practice. Move into Life is a Somatics modality that incorporates elements of movement, meditation, culture, and the environment; it is heavily influenced by Reeve's extensive period of 29 years studying with Suprapto Suryodarmo (Prapto).

Prapto is a Javanese Theravadin Buddhist and movement artist who created the Padepokan Lemah Putih school in Java and is the originator of Joged Amerta (formerly Amerta Movement), which is a ritualistic improvisational art (Putih, 2016). Joged Amerta means 'moving dancing nectar of life,' and is intended to lessen the sense of identification, or individual self, through movement practice (2016d). It aims to help practitioners to 'blossom into one's full potential,' according to Reeve (S. Reeve, 2016d) and eventually into enlightenment. Prapto's training is, as Reeve states, 'a deeply somatic practice, in the sense that it is about all kinds of subjects becoming aware of what movement is from their innermost sense of being alive' (2016d). Reeve also notes a central aspect of Prapto's training is that one must develop their own work, which is how Move into Life originated and was established by Reeve in 1999. Prapto has been an influential teacher, not only for Reeve, but many world-leading somatic practitioners (Bloom et al., 2014).

In addition to Buddhist mindfulness practice, Move into Life incorporates ecological principles. Reeve's experience of living in Java for three years, of moving in different cultures, landscapes, and religious sites across Java, Australia, the USA, and Europe, as well as in her current home of West Dorset, UK have helped to shape the development of her Move into Life training programme (S. Reeve, 2016a). It is a 'foundation programme for embodiment' focused on giving participants a feeling of their 'many and changing selves-in-motion in the environment' - an element that clearly reflects alignment with embodied and situated cognition (S. Reeve, 2016b). The programme is designed as a cycle of workshops, in which participants are led to hone their observational skills toward movement in all environments (individual, social, cultural, ecological, and so on) within which they exist. A major focus of the work is to bring to the forefront a variety of 'lenses' through which to observe oneself and one's movement. One of these lenses is The Environmental/Perceptual Lens, which centres on being a part of a larger context, through 'ecological perception' and 'environmental movement.' It is delivered in a number of outdoor locations. Beyond the foundational programme, Move into Life also includes workshops in 'the ecological lens' (called 'The Ecological Body') which introduce ecological movement and focus on participants finding their independent place within the wider ecology (S. Reeve, 2016e).

Reeve creates 'small-scale ecological performances' of site-specific improvisation that draw directly upon her somatic practice (2011a, p. 64). For her, somatic practices allow one to calibrate within one's life or artistic practice, and to develop an ability to be present within both one's inner life and the broader context or environment - to know one's inner self deeply yet still be able to engage with the outer world politically, socially, and culturally and to have choice about that engagement. 


\subsection{Andrea Olsen}

Andrea Olsen is an improvisational dancer, choreographer, and author who teaches and performs internationally. She holds an MFA in Dance Choreography from the University of Utah and identifies herself as an 'artist-educator' (Olsen, 2015b). Olsen has worked for the past 30 years as a Professor of Dance and the John Elder Professor of Environmental Studies at Middlebury College in Vermont (USA) - as well as at the Middlebury Institute of International Studies in Monterey, California (USA) and as a guest faculty member at Mount Holyoke and Smith Colleges, in addition to her private practice (Consortium, 2014). Her teaching, writing, and performance work engage with experiential anatomy, ecology and the relationship between body and environment, and the discipline of Authentic Movement, ${ }^{2}$ which is her main somatic practice. Since 1979, she has engaged with what, in an interview, she terms her 'three basic practices,' which include Authentic Movement, choreography, and experiential anatomy (Olsen, 2015b). She claimed in an interview that, in addition to Authentic Movement and embodied anatomy, 'my somatic practice would also be about moving out in nature' (ibid). This emphasis on moving in - or with-nature is evident in her making practice, where Olsen draws on (often site-specific) environmental improvisation, experiential anatomy, and $\mathrm{Au}-$ thentic Movement.

Olsen is the creator of the Body and Earth somatic training programme, and is renowned for influential somatics texts on embodied anatomy, Body and Earth: An Experiential Guide (2002), Bodystories: A Guide to Experiential Anatomy (2004), and The Place of Dance: A Somatic Guide to Dancing and Dance Making (2014). 'We understand the connections between body and earth through experience' claims Olsen (Olsen, 2002, p. ix and 189). Her Body and Earth, as a workbook dedicated to the ways which our bodies are both derived from and a part of the natural world, is one example of this experiential environmental practice. Laidlaw and Beer (2018, p. 287) note that, 'Andrea Olsen's Body and Earth programme [is] a programme that uses somatic bodily movement as the main vehicle for knowledge creation and more-thanhuman connection.' Olsen has also developed Body and Earth into a web-based somatic resource that delivers principles of Olsen's training in a mixed-media practice guide (Olsen, 2015a). Research (Laidlaw \& Beer, 2018) argues that Olsen's Body and Earth practice facilitates connection with the more-than-human through its emphasis on environmental movement.

\subsection{Joan Davis}

Joan Davis is somatic practitioner and choreographer based in Bray Wicklow, Ireland, who has been exploring body-based practices for over 40 years (Poynor, 2020a). A pioneer of contemporary dance in Ireland and founder of Dublin Contemporary Dance Theatre in the 1970s, Davis is also a Hakomi Sensorimotor Trauma Psychotherapist and draws on Mindell's Process Oriented Psychology as well as her somatic practices of Authentic Movement and Body-Mind Centering in her creative and therapeutic practice. Her somatic practice draws on these diverse

\footnotetext{
${ }^{2}$ Authentic Movement is a somatic practice created by Mary Starks Whitehouse and further defined and popularized by Janet Adler and Joan Chodorow. It is an improvisational, self-directed form in which movement is guided by inner impulses. It is grounded in a mover/witness dynamic (whether in group/leader or dyad settings), before an 'internal witness' is developed for solo practice (Adler, 2002).
} 
influences to create a situated awareness; as somatics researcher Emma Meehan (2011a) notes in working with Davis, she "introduced the idea of "object relations", a rich field of research in psychotherapy dealing with the relationships between the individual, other people, and the surrounding environment.' Though Meehan (2011a) notes, 'Davis' somatic training does not concentrate on performance, but rather focuses on how this approach can be used in exploring personal and group process,' Davis' somatics-informed creative practice has resulted in 'sitespecific, participative performances that she calls "Maya Lila"' (Meehan, 2011b) as well as screendance works and published books on her work (Abrams, 2019).

Meehan reveals how Davis creates immersive, ecological performances through her somatic movement approaches that facilitate active individual participation in installation environments, 'challenging expectations, perceptions, and actions' (Meehan, 2017, p. 219). Davis's work is situated in her family land and home, Gorse Hill, and is closely tied to the gardens there. The ecology of Gorse Hill is noted as 'a fundamental inspiration and support for all Joan's work' (Poynor, 2020b). Davis recently developed a postgraduate programme in the somatic practices of Authentic Movement and embodied spiritual practice. Of this programme, Mary Abrahams (2019), an American leader in somatic practices, says,

Davis is among a generation of creative professionals in Ireland and across the UK that dedicated their lives to in-depth explorations and research through the silent level (nonwords) processes and expressions of the human body. Davis is among the "rock stars," and she has rightfully earned her honor and fame through decades of creative, intellectual, emotional, and spiritual research that she integrated into a training programme called Origins.

In her own writing, Davis discusses that Origins will cultivate 'an enriched participation with the world' (Keogh \& Davis, 2017, p. 536), illustrating the importance of ecology and environment in Davis' practice.

\subsection{Helen Poynor}

Helen Poynor is a registered dance movement therapist and somatic movement therapist as well as an internationally known teacher, researcher, and artist. She has published widely on her own somatic practice as well as others' and is a teacher for well-recognised somatics training hubs Amerta Movement as well as Tamalpa UK. Poynor's somatics-based movement practice is set in natural environments, and she creates site-specific, improvisational, multidisciplinary, and often autobiographical (Poynor, 2013, 2019) performance works. In addition to studying with Prapto in Java, Poynor has also studied extensively with American somatics pioneer Anna Halprin in Halprin's Life/Art process. She notes that Halprin's work encourages 'understanding of the relationship between the natural world, human beings and dance-making. It analyses the processes used to heighten sensory awareness and engender a kinaesthetic engagement with nature,' an engagement that echoes in Poynor's own somatic practice as well (Poynor, 2009, p. 121).

Indeed, Poynor (2013, p. 169) herself discusses how her practice happens 'both in the studio and in the wider environment,' discussing it within 'the context of her ongoing practice of non-stylized and environmental movement.' She identifies her movement practice as 'specifically, [...] practice in nature' (Poynor 2013, p.174). Poynor created and runs the somatic 
movement education Walk of Life Workshop and Training Programme in the UK on the Jurassic Coast (Poynor, 2020c). In her writing about her practice, Poynor (2013) gives equal attention to describing her physical movement as the environmental landscapes within which the movement occurs. For example, indicating a clear connection with the more-than-human 'bodies,' she writes, 'Moving in tidal sites reminds us that nature tolerates us on its own terms. Situated between microcosm and macrocosm, between limpets and towering crumbling cliffs, we are woven into a complex web of forces and life-forms. How does the physicality of our moving body encounter the materiality of these other bodies?' (Poynor, as quoted in Pitches, 2017, p. 357).

In her words, her 'approach to movement is grounded in an experiential understanding of the structure of the body, an awareness of the relationship between the moving body and the self and of the responsive inter-relationship between body, earth, self and environment' (Poynor, n.d.). It is evident that connection to the environment and earth is central to Poynor's somatic practice.

These are but a few of the leading somatic practitioners that are working in an ecological manner. Other prominent leaders might include Olsen's collaborators and somatic dance educators Caryn McHose and Kevin Frank. Further one might highlight Sondra Fraleigh, founder of Eastwest Somatics, who believes that 'the living body of the earth and our human body are interwoven, and that healing the earth and ourselves will be the major work of the 21 st century' (Fraleigh, 2006). Her Shin Somatics approach 'seeks to develop a relationship with the forces of nature in daily life and through dance' (Cruz Banks \& Marler, 2020). Further, Anna Halprin's engagement with environment through her practice (as highlighted by Poynor above) and her Planetary Dance (Halprin, 1995) are notable additions to the list, as are countless indigenous practices which may be inherently somatic though they existed long before the field was defined (Cruz Banks \& Marler, 2020; Eddy, 2017), among others.

\section{Intersections between somatic practices and environmental empathy: somatics as training in ecological awareness}

What each of these somatic leaders have in common is their commitment to body-based practices situated within the natural environments. By situating these practices within nature, I propose these practitioners facilitate a heightened empathy with the environment (the human and non-humans in our surrounds) as well as with the ecology (or the relationships that exist between these components). And by connecting these practices with that relational awareness, environmental empathy developed through somatic practices leads toward ecological awareness and empathy as well.

As Paula Kramer (2012, p. 85) argues, Reeve, Prapto, and Poynor's processes for example, all engage with cognitive and theoretical constructs "viscerally, rather than (only) "in the head"” and happen in natural environments. As noted above, many somatic practices take this approach, e.g. what Cruz Banks and Marler (2020) call 'somatic research and practices about earth connectivity.' They note, 'Leading somatic thinkers and practitioners such as Conrad (2012) and Halprin (2014) have been advocating for decades that environment engagement and synergy is vital to achieving somatic revelations,' pointing to the importance of ecological 
connection within somatic practices. These approaches to practice do not consider the human form as separate from the environment — not a body removed from typical indoor and manmade environments, or a movement practice displaced from its 'usual' studio or theatre setting into an outdoor, 'site-specific' one. Not dancing 'in' but rather dancing 'with' nature.

As somatic practitioner (and student of Reeve, Poynor, and Prapto) Paula Kramer (2012) argues, moving in this way, with awareness, in nature, is not a 'letting go' of constraints aligned with western studio and stage dance contexts. It is not a 'return to nature' that 'easily results in leaving the body behind rather than making use of its capacities for creative expression, for being present, engaged, and alive,' but rather 'an embodied and receptive engagement' in confederation with the natural environment, which together with the human mover creates a distributed agency of movement and performance-making (2012, p. 91). Echoing Barry's assertion introduced earlier in this article that eco-critics are not engaging with 'a naïve "pretheoretical" notion of nature,' (2002, p.253), Kramer (2012, p.82) argues that this kind of embodied exploration in nature challenges the idea of 'contemporary dance practices in the natural environment as naïve and concerned only with "feeling good and close to nature." She continues, 'Instead it argues for the capacity of some practices to engage with and change how we live in this world' (ibid.).

Furthermore, there is an equanimity here, where the human moving is simply a part of the ongoing environmental dance of which we are all a part. These practices do not claim to 'discover' something new in this relationship, but rather return to what-is-already-there, a knowing that is inherent in being, but is often supressed or repressed in 'civilized' society. As Laidlaw and Beer (2018, p. 287) highlight, 'Current social practices encourage us to identify with only our thinking mind rather than our whole bodies,' and therefore, 'the human-nature divide is unavoidably present even within us.' Reeve (2010, p. 189) also notes the disconnect inherent in Cartesian-based cultures that some somatic practices may rectify, stating Joged Amerta 'pays attention to environmental embodiment and attaches crucial importance to the mutual interdependence and co-creation of organism and environment,' and as such, may 'offer insights for the developing practice of somatic ecology in the West.'

What Reeve identifies as this developing practice has been termed 'somatic ecology' (Bettmann, 2009) by some and 'ecosomatics' (Bauer, 2008; Enghauser, 2007) or 'eco-somatics' (Eddy, 2017; Nelson, 2018; Walla, 2010) by others. The movement's origin has been reported at varying dates. While the idea of 'somatic ecology' was introduced by Thomas Hanna as early as 1976 (Hanna, 1976), Eddy (2017, p. 258) puts the start of eco-somatics as $2008,{ }^{3}$ while as Satu Palokangas (2020, n.p.) claims it emerged 'as a named body' within somatics around 2007. Palokangas notes,

'This natural expansion of somatics has found form through the work of many people, bridging the fields of ecology, dance/movement and activism into work that revives and reconnects. However, this is the work that has always been there, as a way to guide us back home, through our bodies onto the earth. It is there in the indigenous wisdom, in their rituals

\footnotetext{
${ }^{3}$ Eddy does, however, note that Enghauser (2007a, 2007b) used the term 'eco-listening' in relationship to somatic and dance practices.
} 
and practices. It is in the re-cognition that our health and well-being is not separate from the well-being of our environment. (2020, n.p.)

Palokangas is not alone in attempting to define this emerging 'branch' of somatic practices. For example, Nelson (2018, p. 19) argues, 'the application of permaculture principles to embodiment provides a context for eco-somatic practice,' a practice which Eddy (2017, p. 256) defines as 'using somatic movement to appreciate nature and to protect against threats to the environment.' Eddy further argues that 'Eco-somatics refers to somatics applied to addressing environmental issues, but also serves as a call to attune with the earth or more specifically, to become aware of oneself participating with the natural environment,' and emphasizes the interrelation and interdependency between humans and the earth's eco-systems (2017, p. 258).

Indeed, though some argue a distinction between eco-somatics and somatic practices generally (Bauer, 2008; S. Reeve, 2010), others note while this connection with ecology is a major focus of the above-mentioned (and other eco-somatic practitioners') approaches to embodiment, it is implicit in all somatic practices. As Eddy (2009) notes, ecology has been a paradigm connected with somatic practices since the onset, and ecological awareness is a contribution of non-Western (particularly Eastern) influences on early somatic practices. Fortin (2002, p. 134) notes that ecological principles are implicitly a part of all somatic practices, whether they be identified as eco-somatic or not, when she claims, 'Somatics is part of a larger paradigm characterized by emphasis on a whole system perspective, ecology, decentralization of decisionmaking, and a shift from outside authority to self-responsibility' (emphasis mine). Such a connection is not limited only to somatics; indeed, as Keogh and Davis (2017, p. 539) state, 'As human beings, body, spirit, emotion and thought all develop in relationship to each other and in relationship to others and the environment.' Rather, it is merely in the recognition of these organisational systems through somatic practices (Eddy 2009, p. 61), that these practices encourage environmental and ecological empathy. Or, as Susan Bauer notes, 'Ecosomatics can [...] help us to reawaken to our interconnection with nature in a profound and personal way' $(2008$, p. 9).

\section{Eco-somatics and Cognition/Perception}

So then the question arises, how do eco-somatics develop this sense of connection to nature, to the environment, to the more-than-human? An answer may lie in the ways in which ecosomatics emphasises the situated-ness of human cognition within not only the body but also the wider environment. One way in which somatic practices facilitate situated cognitive processes is through a cognitive repatterning that emphasises the balance between inner and outer perception (Laidlaw \& Beer, 2018; Weber, 2018).

Perception is a key element in cognition, and previous research supports that movement and dance may facilitate a refining of sensory perception (Bläsing et al., 2012; Legrand \& Ravn, 2009). Dance science and somatics researcher Nancy Gamboian notes, 'By directing one's attention to the sensation of an experience,' as in somatic practices, awareness and refining of sensory perception develop (1997, p. 5). Shantel Ehrenberg (2015) links perceptual training through focused attention on physical sensation to somatics, while I have earlier argued that the repeated focusing of attention on sensory stimuli in somatics is a form of training one's 
perceptual awareness such that one is able to discern an ever-finer level of detail (Weber, 2018). Supporting this, Olsen states that in general, 'our perceptual range becomes progressively more limited. However, through information and experiential exercises [as in somatics] our perceptual conditioning and habits can expand' (2002, p. 56). Likewise, somatic practitioner Miranda Tufnell claims that those 'with a somatic training develop a refined awareness' of bodily sensation (2017, pp. 140,112). And, as Kramer (2012, p. 85) notes, perception linked to this kind of somatic investigation can have effects on ecological awareness. She argues, 'perception, awareness and receptivity, especially when rooted in a clarified physicality and materiality of the body, allow a mover to work effectively in the natural world without having to fully understand, control or reconnect with it.'

Reeve also emphasises the focus on sensory perception in somatic practices when she discusses her environmental movement training. She claims that 'Environmental movement training provides several tools that may be seen as developing "somatic modes of attention"" (2011a, p. 48). ${ }^{4}$ Situating the terminology in the psychological discourse, this "mode of attention' indicates a discriminating focus of awareness on specific sensory information. For Reeve, these modes of attention come from the perspective of the body, as situated in culture and environment, and differs from other such perspectives by its grounding in movement (2011a, p. 48-49). Her emphasis on movement as central offers what she terms 'a perception of the world that is utterly different from the one that we are generally accustomed to' (2011a: 48). Here, then, at the centre of Reeve's eco-somatic practice is a shift, a deepening, in sensory perception. For her, this refined perception is a direct result of attending to the moving body, to subjective physical sensation - the key unifying element of somatics as a field (ISMETA, 2015).

Perceptual psychology offers some support for how the emphasis on sensory perception in somatic practices can facilitate ecological empathy. Laura Sewall, an ecopsychologist that specialises in perception, argues that ecological perception is a skill that can be developed (Sewall, 1995). Somatics researchers argue Sewall's framework parallels the processes of perceptual training in somatic practices (Enghauser, 2007; Reeve, 2010). In it, Sewall identifies five aspects to training one's ecological perception: learning to attend; perceiving relationships, contexts, and interfaces; developing perceptual flexibility; refining depth perception; and intentionally engaging imagination — each of these has links to somatic practices. For example, somatics offers spaces to attend to sensation, to perceive relationships - or establish connection to self, other, and the environment (Weber 2018), to allow for shifts in - and deepening of-perception (as noted above). Actively engaging the imagination is a hallmark of many somatic practices; many of the pioneers of somatics have centred their practices around specific imaginative visualisation and mental imagery. For example, Lulu Sweigard's Ideokinesis, Erick Franklin's Franklin Method, and Joan Skinner's Skinner Releasing Technique, to name only a few, all have specific imagery exercises at the core of their somatic practice, while other practices such as Authentic Movement engage with the imagery arising from our pre-conscious through embodied movement explorations. Furthermore, highlighting how eco-soma-

\footnotetext{
4 'Somatic modes of attention' is a term used by Reeve but first coined by cultural anthropologist Thomas Csordas (1993), to argue for embodiment, as a product of culture and perceptual experience, as a methodological field.
} 
tics may contribute developing ecological perception through perceiving relationships, contexts, and interfaces, Nelson (2018, p. 19) argues, 'The ecosomatic cross-pollination between the theories and practices of somatics and permaculture is particularly useful, because it empowers us to embrace our individual perceptions while remaining in relationship with systemic patterns and intentional design.'

As I noted above, somatic practices facilitate a sense of connection to self, others, and the environment. This connection requires a particular form of attention, not only a 'kinaesthetic mode of attention, ${ }^{5}$ but one that extends beyond the body and which aims to balance the inner and the outer, or what Olsen terms 'inner and outer awareness' (2002, p. 3). Our capability for balancing typical outer perception with a capacity for inner sensing is 'one of the most thoroughly neglected areas of body education' in Olsen's view (2004, p. 11). Noticing and balancing awareness between inside and out is an integral aspect to somatic practices. As noted above, Reeve calls this developing 'somatic modes of attention,' which she defines as 'culturally elaborated ways of attending to and with one's body in surroundings that include the embodied presence of others' (2010, p. 199). Extending awareness from self to other to environment through somatic practice allows for participants to extend their perceptual acuity, and discern between more nuanced sensing, refining the flow of information and building connections between cognitive subsystems (Weber 2018). One's self does not exist in a vacuum, and the context of one's sensing is both a part in enacting that sensing and imperative to the cognitive patterning trained through somatic practice (Varela et al., 1991; Weber, 2018).

Sewall (1995, p. 207) further argues, 'In relation to developing an ecological consciousness, skilful perception necessarily includes emphasizing perceptual practices that help us to extend our narrow experience of self and to experience sensuality, intimacy, and identification of the external world.' Here, she clearly links perceptual development with a connection to the wider ecological environment. It is arguable that the 'perceptual practices' she mentions could include eco-somatic practices, though she does not identify these herself. Linking the two, Reeve (2010, p. 196) notes, 'As pointed out by perceptual psychologists (Sewall 1995, p. 201) the senses offer a bridge between our inner and outer environments. In order to re-appraise ourselves as 'organisms-in-the-environment', this type of [eco-somatic] investigation may be undertaken with all the senses.' Here, Reeve highlights the contextual, multi-sensory awareness developed in eco-somatic practices.

The emphasis in eco-somatics on moving out in nature, away from the usual indoor environments we humans inhabit, may in fact further the refining of sensory awareness and perception which I argued above somatic practices encourages. As Bauer $(2008$, p. 9) states, 'While somatics develops our kinaesthetic and sensory perceptions, eco-somatics also includes the environment and one's awareness of and relationships with the outer world.' Both perceptual refinement and balancing awareness of inner and outer is central in this simultaneous sensing and contextualising. Olsen has termed this, 'Taking perception out as well as in. Doing changing lenses. Eco-psychology shifts of temporal and spatial scale [...] both inner and outer'

\footnotetext{
${ }^{5}$ I borrow this term from dance researcher Shantel Eherenberg's article, in which she describes a kinaesthetic mode of attention as 'a mode of intentional consciousness while dancing' which is focused on bodily sensation, feelings, and embodied translation or problem-solving processes (2015: 44-46).
} 
(Olsen 2015). In another example, Reeve (2010, p. 195) similarly notes, 'Joged Amerta is a practice that encourages an equal alertness to both the inner landscape of the participants and to their external environment.' In arguing this, Reeve emphasises the equanimity between the inner, felt, bodily sensation and the external environment - neither one taking perceptual priority, both recognised as 'nature' in a state of constant becoming. As she further articulates, 'By experiencing our changing bodies as part of a changing environment, we diminish the sense of a rigid boundary between the experience of self and that of the environment' (Reeve 2010, p. 194), lending further support to the argument that eco-somatic practices cultivate ecological empathy.

Moreover, Nala Walla suggests that, 'The practice of eco-somatics heals the separation between mind, body, and earth by encouraging direct sensory perception of one's body both in the natural environment and as the natural environment' (2010, p. 151, original emphasis). This sense of body in and as environment is pervasive within eco-somatic practices. It is this deep connection to the environment that allows practitioners to realise 'we are nature too,' as Olsen claimed in a radio interview and often in Body and Earth classes (Lindolm et al., 2014; Olsen, 2014, field notes 27.7.16). In my experience of her 'Body and Earth' practice, Olsen named the 'Body is Earth/humans are nature too' as a central concept (field notes 27.07.16). Similarly, Helen Poynor notes,

Giving oneself time to experience a receptive and reciprocal relationship with nature offers a way to return to oneself. It allows us to 're-member' that we are an intrinsic part of a larger body, that our muscles and our bones, our breath and our blood are made of the same elements as the living environment around us and that we have kinship with earth and rock, with sky and wind, with rain and sea. (2018, p. 170)

Reeve (2010, p. 200) argues eco-somatic practice challenges our acculturated experience of being in control of and separate from nature. She argues, 'The cultivation of environmental awareness through movement' develops reflexivity and ecological empathy (ibid.). And, as Bauer reiterates, 'Truly ecosomatic approaches intentionally ground our practices in the body by encouraging direct sensory perception of one's body as the natural environment.' (Bauer 2008, p. 9).

This reciprocal kinship between human and nature is a prime example of how ecosomatic practices align with ecocritical understandings. As Reeve (2010, p. 200) observes,

Ecological movement ostensibly has nothing to do with carbon emissions or global warming. But, in its emphasis on community and context, on being 'among' and being 'part of', on being constantly in flux in a world that envelops us (rather than being scenery or a backdrop), it encourages a sense of belonging rather than longing and a sense of the world as a shared habitat rather than owned territory. This sense of belonging and sharing is profoundly ecological.

It is through this sense of confederation (Kramer, 2012) with nature, developed through an embodied cognitive refining of sensory perception in the environment, that I hypothesise ecosomatic practices develop environmental empathy. As Bettmann (2009) argues, connecting with nature, whether through somatics or not, requires developing embodied knowledge that is shared with all entities - echoing paradigms of embodied and situated cognition. Bettmann 
further argues that recognition of this shared knowledge develops empathy. This environmental empathy — or what Nelson (2018, p. 19) terms 'an ethical attitude of compassion,' Bauer (2008, p. 9) calls 'heartfelt stewardship of our planet,' and Poynor (2018, p. 169) articulates as 'renewed sense of kinship with the natural world' - is clearly a pervasive effect of ecosomatic practices.

\section{Conclusion}

This article has discussed how the philosophies of eco-criticism, situated cognition, and somatic practices weave together in eco-somatics. While further research in ecosomatic practices may use situated cognition tools to identify in-depth the processes at work in developing environmental empathy, this article has presented an explanatory hypothesis of how somatic practices might encourage environmental empathy through perceptual training in natural environments. It offered an overview of some leading and influential somatic practitioners whose environmental embodiment practices have paved the way for eco-somatic practices to flourish and impact the greater field of somatic practices generally. Further, in bringing pan-somatic perspectives together, it has identified how eco-somatic practices address and rectify the binary between human and nature, through positioning the body both in and as environment. In so doing, eco-somatic practices, like somatic practices more generally, are refining sensory perception through embodied and situated cognition. By focusing on attending to sensory stimuli occurring both within and outside of the body, and situating perceptual awareness within a larger ecology, eco-somatic practices balance both inner and outer awareness. As such, I propose that somatic practices not only enhance perceptual cognitive processes, but create a sense of kinship and confederation with the environment and earth as a whole, ultimately developing ecological empathy.

\section{References}

Abram, D. (1996). The Spell of the Sensuous: Perception and Language in a More-than-Human World. Penguin Random House.

Abrams, M. (2019). Origins | Somatic Psychotherapy Today. Somatic Psychotherapy Today, November. https://somaticpsychotherapytoday.com/origins-2/

Adler, J. (2002). Offering from the Conscious Body: The Discipline of Authentic Movement. Inner Traditions.

Barry, P. (2002). Beginning Theory: An Introduction to Literary and Cultural Theory. Manchester University Press.

Batson, G., \& Wilson, M. (2014). Body and Mind in Motion: dance and neuroscience in conversation. Intellect.

Bauer, S. (2008). Body and Earth as One. Conscious Dancer, 8-9.

Bettmann, R. (2009). Somatic Ecology: Somatics, Nature, Humanity and the Human Body (9783639150254): Bettmann, Robert: Books. VDM Verlag. https://www.amazon.com/Somatic -Ecology-Somatics-Nature-Humanity/dp/3639150252 
Bläsing, B., Calvo-Merino, B., Cross, E. S., Jola, C., Honisch, J., \& Stevens, C. J. (2012). Neurocognitive control in dance perception and performance. Acta Psychologica, 139(2), 300308. https://doi.org/http://dx.doi.org/10.1016/j.actpsy.2011.12.005

Bloom, K., Galanter, M., \& Reeve, S. (Eds.). (2014). Embodied Lives - Reflections on the Influence of Suprapto Suryodarmo and Amerta Movement. Triarchy Press. https://www.triarchypress.net/ embodiedlives.html

Brodie, J., \& Lobel, E. (2004). Integrating Fundamental Principles Underlying Somatic Practices into the Dance Technique Class. Journal of Dance Education, 4(3), 80-87.

Brodie, J., \& Lobel, E. (2006). Somatics in Dance, Dance in Somatics. Journal of Dance Education, $6(3), 69-71$.

Brodie, J., \& Lobel, E. (2012). Dance and Somatics: Mind-Body Principles of Teaching and Performance. McFarland \& Company.

Clifford, J. (2008). Traveling cultures. In The Cultural Geography Reader (pp. 328-336). Routledge.

Consortium, F. C. (2014). Five College Dance Department: Andrea Olsen. https://www. fivecolleges.edu/dance/facultystaff/guest-artists/andrea-olsen

Crutzen P.J. (2006) The "Anthropocene". In: Ehlers E., Krafft T. (eds) Earth System Science in the Anthropocene. Springer, Berlin, Heidelberg. https://doi.org/10.1007/3-540-26590-2_3

Cruz Banks, O., \& Marler, M. (2020). Souls, soil, and soma: Memoirs of Japan. In Amanda Williamson \& B. Sellers-Young (Eds.), Spiritual Herstories: Call of the Soul in Dance Research. Intellect Books.

Eddy, M. (2002). Somatic Practices and Dance: Global Influences. Dance Research Journal, 34(2), 46-62. http://www.jstor.org/stable/1478459 .

Eddy, M. (2009). A Brief History of Somatic Practices and Dance: Historical Development of the Field of Somatic Education and its Relationship to Dance. Journal of Dance and Somatic Practices, 1(1), 5-27.

Eddy, M. (2017). Mindful movement: the evolution of the somatic arts and conscious action. Intellect.

Ehrenberg, S. (2015). A Kinesthetic Mode of Attention in Contemporary Dance Practice. Dance Research Journal, 47(2), 43-61. https://doi.org/10.1017/S0149767715000212

Enghauser, R. (2007). Developing Listening Bodies in the Dance Technique Class. Journal of Physical Education, Recreation, and Dance, 78(6), 33-54.

Fortin, S. (2002). Living in movement: development of somatic practices in different cultures. Journal of Dance Education, 2(2), 128-136.

Fraleigh, S. (2006). Eastwest Somatics: Institute for Dance and Movement Studies: About the Director.

Gamboian, N. (1997). The Use of Somatic training to improve pelvic tilt and lumbar lordosis alignment during quiet stance and dynamic dance movement: Vol. PhD. University of Oregon.

Gibbs, R. (2005). Embodiment and Cognitive Science. Caimbridge University Press. 
Halprin, A. (1995). Moving Toward Life: Five Decades of Transformational Dance. Wesleyan University Press.

Hanna, T. (1970). Bodies in Revolt: A Primer in Somatic Thinking. Holt Reinhart.

Hanna, T. (1976). The Field of Somatics. Somatics: Magazine-Journal of the Bodily Arts and Sciences, 1(1), 30-34.

Hanna, T. (1979). The Body of Life: Creating New Pathways for Sensory Awareness in Movement. Healing Arts Press.

Hungerford, H. R. \& Volk, T. L. (1990). Changing learner behavior through environmental education. The Journal of Environmental Education, 21(3), 8-21.

Johnson, D. H. (1986). Principles Versus Techniques: Towards The Unity Of The Somatics Field. Somatics, VI, 4-8. http://www.donhanlonjohnson.com/articles/principles.htm

Keogh, A. F., \& Davis, J. (2017). Cultivating the Felt Sense of Wellbeing: How We Know We Are Well. In The Oxford Handbook of Dance and Wellbeing (pp. 535-548). Oxford University Press.

Kramer, P. (2012). Bodies, rivers, rocks and trees: Meeting agentic materiality in contemporary outdoor dance practices. Performance Research, 17(4), 83-91. https://doi.org/10.1080/13528 165.2012 .712316

Laidlaw, B., \& Beer, T. (2018). Dancing to (re)connect: Somatic dance experiences as a medium of connection with the more-thanhuman. Choreographic Practices, 9(2), 283-309. https://doi.org/10.1386/chor.9.2.283_1

Legrand, D., \& Ravn, S. (2009). Perceiving Subjectivity in Bodily Movement: The Case of Dancers. Phenomenology and the Cognitive Sciences, 8(3), 389-408.

Lindolm, J., Van Wing, S., \& Olsen, A. (2014). Why We Dance - interview with Andrea Olsen $(28$ Apr 201). Vermont Public Radio. http://digital.vpr.net/post/why-we-dance\#stream/0

Lithoxoidou, L. S., Georgopoulos, A. D., Dimitriou, A. T., \& Xenitidou, S. C. (2017). " Trees Have a Soul Too!" Developing Empathy and Environmental Values in Early Childhood. International Journal of Early Childhood Environmental Education, 5(1), 68-88.

Meehan, E. (2011a). Somatic Practices as Creative and Therapeutic Tools|IAHIP. Irish Association of Humanistic and Integrative Psychotherapy, 63. https://iahip.org/inside-out/issue-63-spring2011/somatic-practices-as-creative-and-therapeutic-tools

Meehan, E. (2011b). Visuality, discipline and somatic practices: The "Maya Lila" performance project of Joan Davis. Journal of Dance and Somatic Practices, 2(2), 219-232. https://doi.org/10.1386/jdsp.2.2.219_1

Meehan, E. (2017). Immersive performance and somatic practices: Joan davis and the maya lila project. Choreographic Practices, 8(2), 219-238. https://doi.org/10.1386/chor.8.2.219_1

Nelson, M. (2018). Embodied ecology: The eco-somatics of permaculture. Choreographic Practices, 9(1), 17-30. https://doi.org/10.1386/chor.9.1.17_1

Olsen, A. (2002). Body and earth : an experiential guide (J. Elder (Ed.)). Lebanon, NH : University Press. 
Olsen, A. (2004). Bodystories : a guide to experiential anatomy. In C. McHose (Ed.), Body stories ("Expanded). Hanover, NH : University Press of New England.

Olsen, A. (2014). The place of dance : a somatic guide to dancing and dance making (C. McHose author (Ed.)).

Olsen, A. (2015a). Body and Earth. http://www.body-earth.org/

Olsen, A. (2015b). Personal interview with Rebecca Weber. 19 October.

Palokangas, S. (2020). Ecosomatics. https://satupalokangas.com/ecosomatics

Pitches, J. (2017). Training and ... the wild(erness). Theatre, Dance and Performance Training, 8(3), 356-359. https://doi.org/10.1080/19443927.2017.1370275

Poynor, H. (n.d.). Walk of Life - Movement Workshops with Helen Poynor. Retrieved July 14, 2020, from http://www.walkoflife.co.uk/training.html

Poynor, H. (2009). Anna Halprin and the Sea Ranch Collective, an embodied engagement with place. Journal of Dance \& Somatic Practices, 1(1), 121-132. https://doi.org/10.1386/jdsp. 1.1.121_1

Poynor, H. (2013). Landscapes of loss: Moving and mourning - An autobiographical account. Journal of Dance \& Somatic Practices, 5(2), 169-177. https://doi.org/10.1386/jdsp.5.2.169_1

Poynor, H. (2018). Earth, tree, rock and sea. Journal of Dance and Somatic Practices, 10(2), 169173. https://doi.org/10.1386/jdsp.10.2.169_1

Poynor, H. (2019). All fathers are fictional: These are not my Father's Shoes - A practitioner's reflections on the process of creating autobiographical performance. Journal of Dance and Somatic Practices, 11(2), 227-234. https://doi.org/10.1386/jdsp_00007_1

Poynor, H. (2020a). About Gorse Hill. https://www.gorsehill.net/about

Poynor, H. (2020b). Gorsehill Garden | Gorse Hill. https://www.gorsehill.net/gorsehill-garden

Poynor, H. (2020c). Walk of Life - Movement Workshops with Helen Poynor. http://www.walko flife.co.uk/training.html

Putih, P. L. (2016). Joged Amerta: Celebration Ethnic Art in Time 2016 (sic). http://www.moveintolife.com/uploads/1/3/9/6/13969833/prapto_program2016-1.pdf

Reeve, S. (n.d.). On the way to Regenerative Choreography. Choreographic Practices.

Reeve, S. (2010). Reading, Gardening and "Non-Self": Joged Amerta and its emerging influence on ecological somatic practice. Journal of Dance and Somatic Practices, 2(2), 189-203. https://doi.org/10.1386/jdsp.2.2.189_1

Reeve, S. (2011a). Nine Ways of Seeing a Body (I. C. P. ebrary (Ed.)). Axminster : Triarchy Press.

Reeve, S. (2011b). Reading, Gardening and "Non-Self”: Joged Amerta and its emerging influence on ecological somatic practice. Journal of Dance and Somatic Practices, 2(2), 189-203. https://doi.org/10.1386/jdsp.2.2.189_1

Reeve, S. (2013). Body and Performance Ways of Being a Body. In S. C. Reeve (Ed.), Body and Performance. Devon : Triarchy Press. 
Reeve, S. (2014a). Make Less the Hoping . In K. Bloom, M. Margit Galanter, \& S. Reeve (Eds.), Embodied Lives: Reflections on the influence of Suprapto Suryodarmo and Amerta Movement (pp. 67-74). Triarchy Press.

Reeve, S. (2014b). The Sacrum and the Sacred: mutual transformation of performer and site through ecological movement in sacred sites (eds), Bristol: Intellect . In A Williamson, G. Batson, S. Whatley, \& R. Weber (Eds.), Dance, Somatics and Spiritualities: Contemporary Sacred Narratives (pp. 417-437). Intellect.

Reeve, S. (2015). Moving beyond inscription to incorporation': the four dynamics of ecological movement in site-specific performance. In V. Hunter (Ed.), Moving Sites: Investigating SiteSpecific Dance Performance (pp. 310-327). Routledge.

Reeve, S. (2016a). About Sandra Reeve. http://www.moveintolife.com/about-sandra-reeve.html

Reeve, S. (2016b). Move Into Life. http://www.moveintolife.com/

Reeve, S. (2016c). Movement Psychotherapy. http://www.moveintolife.com/therapy.html

Reeve, S. (2016d). Personal interview with Rebecca Weber. 4 March.

Reeve, S. (2016e). The Annual Move Into Life Workshop Cycle. http://www.moveintolife. com/workshop-cycle.html

Robbins, P., \& Aydede, M. (2012). A Short Primer on Situated Cognition. In P. Robbins \& M. Aydede (Eds.), Cambridge Handbook of Situated Cognition (Vol. 3, Issues 1-2, pp. 3-12). Cambridge University Press.

Rosenzweig, C., Karoly, D., Vicarelli, M. et al. Attributing physical and biological impacts to anthropogenic climate change. Nature 453,353-357 (2008). https://doi.org/10.1038 /nature06937

Schultz, P. (2002). Inclusion with nature: The psychology of human-nature relations. In P. Schmuck \& P. Schultz (Eds.), Psychology of Sustainable Development (pp. 61-78). Kluwer Academic Publishers.

Sewall, L. (1995). The skill of ecological perception. In Ecopsychology: Restoring the earth, healing the mind (pp. 201-215).

Shapiro, L. (2011). Embodied Cognition. Routledge.

Shultis, J., \& Heffner, S. (2016). Hegemonic and emerging concepts of conservation: A critical examination of barriers to incorporating Indigenous perspectives in protected area conservation policies and practice. Journal of Sustainable Tourism, 24(8 \& 9), 1227-1242.

Sobel, D. (1996). Beyond ecophobia. Great Barrington, MA: Orion Society.

Stainton Rogers, Wendy. (2009) "Research Methodology" in Fox, D., Prilleltensky, I, and Austin, S. (eds) Critical Psychology: An Introduction (2 ${ }^{\text {nd }}$ Ed.). Sage, Los Angeles. pp.335-354

Taylor, P. (2011). Respect for Nature, A Theory of Environmental Ethics. Princeton, NJ: Princeton University Press

Tam, K. P. (2013). Dispositional empathy with nature. Journal of environmental psychology, 35, 92-104. 
Thomas, H. (1995). Formulating a sociology of dance. In Dance, Modernity, and Culture: Explorations in the Sociology of Dance (pp. 1-30). Routledge.

Tufnell, M. (2017). When I Open My Eyes: Dance Health Imagination. Dance Books Ltd.

Vannini, P., \& Waskul, D. (2006). Body/Embodiment: Symbolic Interaction and the Sociology of the Body -. Routledge. https://www.routledge.com/BodyEmbodiment-Symbolic-Interactionand-the-Sociology-of-the-Body/Vannini-Waskul/p/book/9780754647263

Varela, F., Thompson, E., \& Rosch, E. (1991). The Embodied Mind: Cognitive Science and Human Experience. MIT Press.

Walla, N. (2010). Body as place: A somatic guide to re-indigenization. In M. Keogh (Ed.), Hope Beneath Our Feet: Restoring Our Place in the Natural World (pp. 150-157). North Atlantic Books.

Weber, R. (2009). Integrating semi-structured somatic practices and contemporary dance technique training. Journal of Dance and Somatic Practices, 1(2), 237-254.

Weber, R. (2018). Somatics, Creativity, and Choreography: Creative Cognition in Somatics-based Contemporary Dance: Vol. PhD. Coventry University.

Weber, R. (2019). Somatic Movement Dance Education: A Feminist, Cognitive, Phenomenological Perspective on Creativity in Dance. In K. Bond \& S. Gardner (Eds.), Dance and the Quality of Life (pp. 307-324). Springer. https://doi.org/10.1007/978-3-319-95699-2_18

Wilson, R. A., \& Foglia, L. (2011). Embodied Cognition. In Stanford Encyclopedia of Philosophy (Vol. 2015, Issue 31 May 2015). Stanford University.

Rebecca Weber (PhD, MFA, MA, RSME, RSDE, RSMT, THE, FHEA) investigates intersections between dance, science, and somatics from theoretical, practical, and artistic approaches. She is currently a Lecturer in Dance Studies at the University of Auckland and course director for their Masters in Dance Movement Therapy. Weber holds a PhD in Dance Psychology from Coventry University, funded by the Leverhulme Trust. She is a registered somatic movement and somatic dance educator who has published widely, including in Dance and the Quality of Life; Research in Dance Education; Multimodal Perspectives in the Performing Arts; The Journal of Dance and Somatic Practices; Dance, Movement and Spiritualities; and the anthology Dance, Somatics, and Spiritualities: Contemporary Sacred Narratives, which she co-edited. As director of Somanaut Dance, her creative work has been presented internationally and supported by Dance/USA, Dance/UP, World Dance Alliance Americas, Decoda, Mascher Space Co-operative, the Rebecca Skelton Fund, and others. In addition to being Director of Somanaut Dance and Co-Director of Project Trans(m)it, Weber is also an Associate Editor of Dance, Movement and Spiritualities, and Board Member of Carolina Dancer Wellness. www.somanautdance.com $\mid$ www.projecttransmit.com 